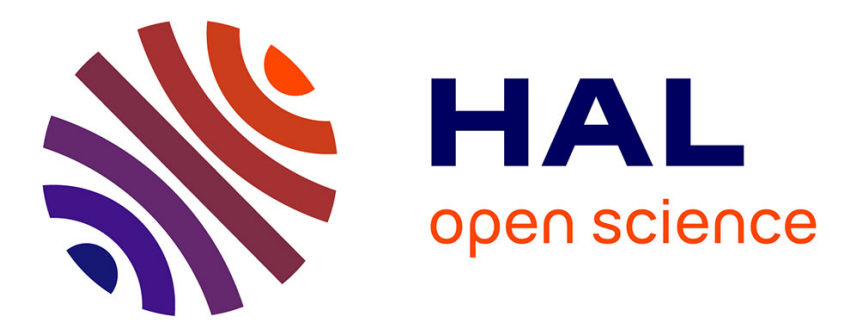

\title{
Root system architecture: from its representation to the study of its elaboration
}

\author{
Loïc Pagès
}

\section{To cite this version:}

Loïc Pagès. Root system architecture: from its representation to the study of its elaboration.

Agronomie, 1999, 19 (3-4), pp.295-304. hal-00885931

\section{HAL Id: hal-00885931 \\ https://hal.science/hal-00885931}

Submitted on 1 Jan 1999

HAL is a multi-disciplinary open access archive for the deposit and dissemination of scientific research documents, whether they are published or not. The documents may come from teaching and research institutions in France or abroad, or from public or private research centers.
L'archive ouverte pluridisciplinaire HAL, est destinée au dépôt et à la diffusion de documents scientifiques de niveau recherche, publiés ou non, émanant des établissements d'enseignement et de recherche français ou étrangers, des laboratoires publics ou privés. 


\title{
Review article
}

\section{Root system architecture: from its representation to the study of its elaboration}

\author{
Loïc Pagès* \\ Écophysiologie et horticulture, Inra, centre d'Avignon, site Agroparc, 84914 Avignon cedex 9, France
}

(Received 12 November 1998; accepted 19 January 1999)

\begin{abstract}
Modelling the architecture of the root system is a recent approach, since almost all such models have appeared during the last 10 years. In a short review of these architectural models, we define several steps in their evolution, which also correspond to different goals. The main basic idea was to translate and to combine morphogenetic rules, described at the root level, in order to produce a quantitative representation of the global object: the root system. The inclusion of stochastic processes appeared to be an economic way to simulate realistic root systems, staying at this organisation level, because of the unpredictable characteristics of some developmental processes, which lead to large variations from one root system to another. In several applications, these models were shown to be helpful for integrating knowledge at the root level regarding soil-root interactions. In the most recent works, a more integrated approach is proposed, in which the components of the root system appear according to a morphogenetic programme, and interact by contributing and responding to the endogenous context of resource availability. (@ Inra/Elsevier, Paris.)
\end{abstract}

\section{architecture / carbohydrate availability / model / root system / soil-root interaction}

Résumé - Architecture du système racinaire : de sa représentation à l'étude de son élaboration. La modélisation de l'architecture des systèmes racinaires est une démarche récente, puisque presque tous les modèles sont apparus dans les dix dernières années. Dans une courte revue de ces modèles nous définissons quelques étapes qui nous semblent importantes au cours de leur évolution. Ces étapes correspondent aussi à différents objectifs de modélisation. L'idée majeure de ces modèles a été de traduire et de combiner des règles morphogénétiques décrites au niveau de la racine pour produire des représentations quantitatives de l'objet dans sa globalité: le système racinaire. L'inclusion de processus stochastiques dans ces modèles est apparue comme un moyen économique de simuler des systèmes racinaires réalistes, tout en restant au même niveau d'organisation (celui de la racine), en raison du caractère imprévisible des caractéristiques de certains processus de développement. Ce caractère non prévisible peut en effet induire de grandes différences d'un système racinaire à l'autre. Différentes études ont montré que ces modèles sont des outils utiles à l'intégration des connaissances acquises au niveau de la racine en ce qui concerne ses interactions avec le sol. Dans les travaux les plus récents, une démarche plus intégrée est proposée, dans laquelle les composants du système racinaire, qui apparaissent selon un

\section{Communicated by Gérard Guyot (Avignon, France)}

*Pages@avignon.inra.fr 
programme morphogénétique, interagissent en contribuant et répondant en même temps au contexte endogène de disponibilité en photo-assimilats. (C Inra/Elsevier, Paris.)

architecture / disponibilité en assimilats / interaction sol-racine / modèle / système racinaire

\section{Introduction}

Representing the morphology of root systems is a recurrent need for investigating their function in the soil, since this function is highly dependent on morphological characteristics. As soil is a very heterogeneous medium, in which resources are generally in limiting amounts and only mobile at rather short distances (from $\mathrm{mm}$ to $\mathrm{dm}$ ), the question 'Where are the roots?' is a crucial one.

In order to answer this question, the traditional description of the root systems made by agronomists consisted of maps of the distribution of root length density in the soil. Root length density was generally expressed versus depth, giving a onedimensional root length density profile (see for example $[1,15,16])$. This method of describing root systems was the consequence of several constraints. From an experimental point of view, classical methods for observing the root system (monoliths, soil cores or trench wall methods) give a direct access to root length density, because a volume (or a surface) of soil is excavated, and the root length inside the volume or behind the surface is estimated. Furthermore, these samplings generally concern the root system of a crop, and not those of isolated plants. In this case, the plant to root relationship is not described. From a conceptual point of view, these descriptions have been used directly in uptake models in which the root uptake is described via a root sink term directly related to the root length density (see for example [3] for nutrients, or [13] for water).

However, this approach has several drawbacks. Root length density is a variable which is essentially associated with the soil, generally with an implicit spatial scale. Therefore, its meaning (value and variance distribution) is dependent on the actual scale at which it is considered $\left(\mathrm{cm}^{3}, \mathrm{dm}^{3}\right.$, or $\left.\mathrm{m}^{3}\right)$.
Moreover, relative to the root system, the root length density is an abstract variable, and presents no straightforward relationship with concepts referring to the root system development (e.g. growth rate, growth direction, branching density). Finally, it is worth noting that many recent works have shown the importance of the between- and along-root variations in uptake capacities (e.g. review by Waisel and Eshel [35]). Therefore, considering all roots as identical through the synthetic variable 'root length density' and neglecting the between-root connections is an oversimplification which leads to poor approximations in many circumstances. Water uptake mechanistic models have been recently developed in which the precise locations of the roots are specified [18] and in which between-root differences, as well as between-root connections, are taken into account $[10,11]$. These models rely on a more detailed description of the root system morphology.

There is no doubt that modelling the architecture of the root system is a way to provide a more specific representation of the uptake system, allowing new insights to be gained. In contrast to the approaches already described, these architectural models explicitly consider the locations and connections of the different axes (roots) that make up the root system. Each root of the system is encoded as a succession of segments and nodes which contain spatial and structural information (e.g. spatial co-ordinates, age, diameter, branching order, links with other segments) [23]. This modelling approach is a rather recent idea, which appeared with the pioneer work of Lungley [20]. His model was very simple, devoted to the simulation of planar branching systems. Interestingly, he used his model to calculate root length density profiles, assuming a radial symmetry of the root system.

Since this pioneer work, many advances have been made during the last 20 years. In this short 
review, we intend to show some of the main steps in this evolution. Citing these different models, we intend in particular to show that the main goals of these models have also changed. At the beginning, they were mainly devoted to the representation of the root system as an input to uptake model. They are gradually becoming tools for studying some of the factors that determine the root system architecture itself.

\section{A common basis: phenomenological models which translate and combine morphogenetic rules}

The basic motivation of root system architecture modellers (from Lungley, [20]) is that the development of the root system, although plastic from a spatial (or dimensional) point of view, is also highly organised if one considers the temporal succession of events and the topological arrangement of its components. This strong temporal (successional) and topological structuration is related to what is often called the 'morphogenetic programme', which leads to 'unités architecturales' [2, 4]. This organised structure justifies a modelling approach in which the extension of the root system can be simulated by production rules [31] defined at the plant and plant entity level, instead of considering them as originating from the soil (as in root length density models). These rules define the transformation of the different plant organs during a time step. They are the formal translation of morphogenetic processes which are experienced by the different organs through time: growth, branching, decay, etc.

In order to define these basic rules, it is necessary to achieve an architectural analysis of the global root system. This analysis leads to the identification of the following two levels of structuration within the system.

1) Components (the roots) categorised in several types, each root type exhibiting some specific characteristics, behaviours and topological relationships with other root types. All these characteris- tics are specified by a set of parameters associated to each root type.

2) Developmental processes that lead to the appearance, transformation and disappearance of these components (formalising for instance branching, growth, decay). These edification processes (production rules) are applied to the different roots with quantitative variations specified through the parameters of each root type.

Almost all architectural models of the root system that have been developed up to now $[7,9,14$, $20,22,23,27]$ can be considered as particular cases in this general frame.

The first step of the architectural analysis (i.e. defining the components and grouping them into a root typology) is very important because the different root types can be compared to different organs in the shoot system: they have different specific characteristics and behaviours. These heterogeneities were described a long time ago on root systems, and the name 'heterorhizy' was given by Noelle in 1905 (Barlow, pers. comm.). On the maize root system, for instance, nodal roots grow throughout the whole life of the plant, with a high growth rate (up to $5 \mathrm{~cm} / \mathrm{d}$ ), whereas the finer roots grow over a few days, and at a much slower rate (some $\mathrm{mm} / \mathrm{d}$ ) $[28,30]$. Strong variations are also found for other criteria, such as growth direction and tropism, branching characteristics, life duration, etc. Root typologies have been published recently for different tree species (see $[2,17,19$, 34]) emphasising the specificity of their developmental characteristics. In most architectural models, the notion of root type is confounded with the branching order [7, 9] but it can be extended [27, 34].

The second aspect of the architectural analysis (through the dynamic processes) can be exemplified by two processes leading to the creation of new roots in root systems: i) emergence of nodal roots on maize, which occur at the basal phytomers of the plant during its development, and ii) acropetal branching of existing roots, a very common way of branching. Both processes are examples of stable rules, although quantitative applications are modulated by environmental char- 
acteristics. Emergence of nodal roots occurs gradually, in an ordered way, from the first basal phytomer upward. The rank of the phytomer that gives rise to nodal roots at a given moment is closely related to the cumulated thermal time experienced by the plant [26]. Acropetal branching of the roots is also a sequential emergence of new roots at some centimetres behind the apex of the mother root. In several models $[20,23]$, this process has been simulated by assuming that lateral roots (whose type depends on the type of its bearing root) appear at a fixed distance to the apex of the bearing root.

In the different models, various rules have been considered to simulate the multiple processes that concur to the edification of different root systems (figure I). On cereal root systems, rules concerning the emergence of nodal roots have been emphasised ([9] on wheat; [26] on maize). Rules simulating root decay have been suggested [27, 34] for simulating tree root systems, for which this process is particularly important.

\section{Inclusion of several stochastic processes}

It is interesting to note that of the various architectural models that have been proposed during the last 10 years $[6,7,9,14,21,23,24]$, none is strict- ly deterministic. They all include one or several stochastic processes. These processes have been included because the models aim to simulate particular objects (root systems), at a given level of organisation in which the particular issue of the simulation retains some unpredictable characteristics.

For example, when a new branch emerges, say during acropetal branching on a given root, the radial position of this new branch is largely unpredictable. It is not fixed, as in the case of shoot systems, by phyllotaxis rules, which precisely determine the position of the branches around their bearing axis. Therefore, in the absence of a clear rule determining a rhizotaxis pattern, existing models draw a radial position at random from a uniform distribution (e.g. [7, 9]).

The simulation of root trajectories is another example. In several models [7, 9, 23], the bending of roots is simulated. This is achieved by simply adding a random noise to the growth direction of the root axis, for each growth increment. The real underlying process, generating the root bending during growth, is related to its growth movements (nutation), and to the multiple deflections due to mechanical obstacles that the root meets. The deterministic simulation of these processes would require additional knowledge of these complex phenomena and consideration of the soil characteristics at a very small scale $(0.1-1 \mathrm{~mm})$. Stochastic modelling is an economical way to render the mor-

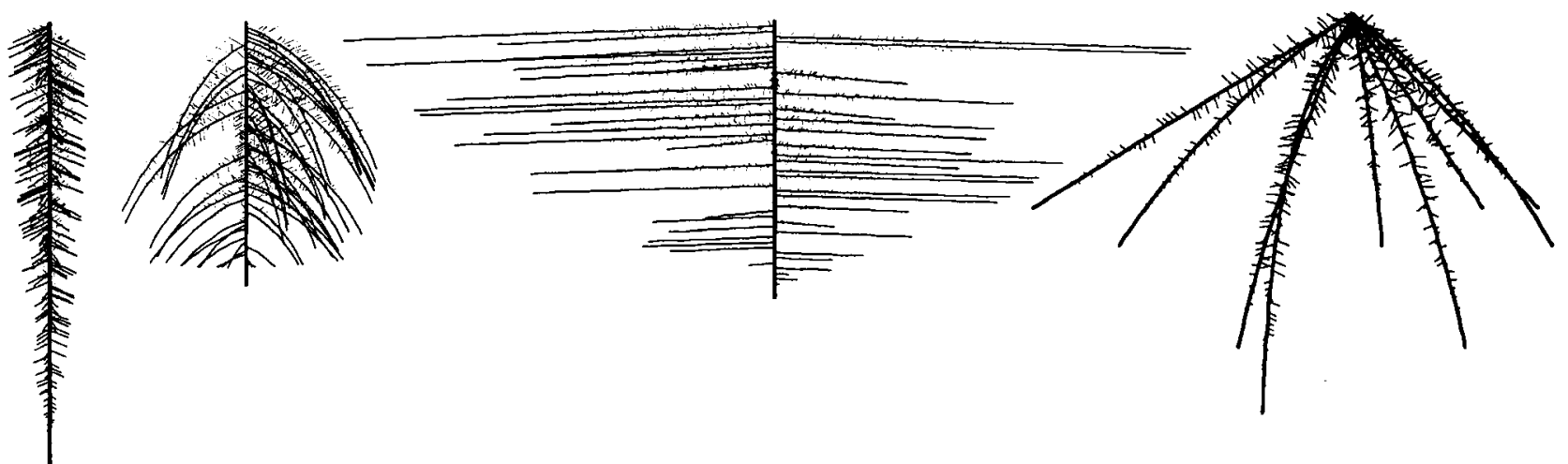

Figure 1. Variations in the root system morphology, as it can be simulated with a simple model based on morphogenetic rules (after [23]). 
phological consequences of such complex and microscopic phenomena (figure 2).

A third example of the application of stochastic processes concerns root elongation. Many authors have demonstrated the important variations that exist in the growth potential of different roots, even when they belong to the same root type. In particular, neighbouring roots appearing at about the same time and position on the same mother axis may have different growth potentials. Pagès et al. [24, 27] have suggested drawing growth characteristics at random from given distributions for each new root at the time of emergence, in order to account for these important local variations (figure 2). Once again, the deterministic simulation of these differences in growth potential, if one assumes that such a simulation is possible, would require at least the description of the micro-environment (endogenous and exogenous) of each root. This type of fine description falls out of the scope of existing models.

The inclusion of such stochastic processes in the models has important consequences. Because of the stochastic processes, the simulated root systems will all be different from one to another. Therefore, the models can simulate the distributions of specific variables by making a number of runs.

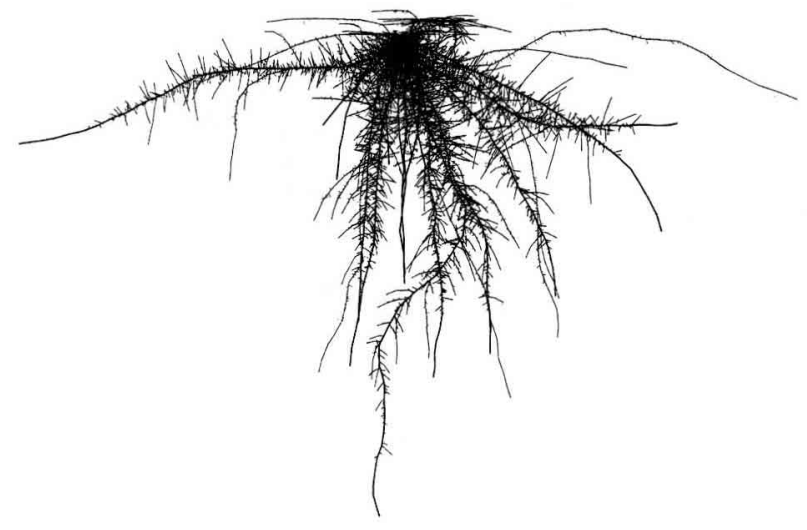

Figure 2. The inclusion of stochastic processes in architectural models allows us to simulate root bending and the high variations observed in lateral root lengths (after [26]).

\section{Taking into account the exogenous environment (interactions with the soil)}

It is very common, and obvious, to say that development of root systems is sensitive to the soil environment. Part of the well-known plasticity of root systems is related to the heterogeneous soil environment.

Even if architectural models started from a plantfocused point of view, several authors [7, 9, 23] have shown that these architectural models could be helpful tools for investigating the soil-root interactions. Each meristem of the whole theoretical root system has a given position in space that is permanently updated during the simulation, by the elongation function. In order to describe the soil-root interactions, it is necessary to have in addition a map of the soil properties (either static or transient), and sub-models describing the relationship between the developmental processes (e.g. growth) and the local soil properties.

This modelling approach allows a link to be made between local phenomena, at the root tip level, and the resulting global morphology of the root system (figure 3). It has been mainly used for describing the response of growth to the local soil temperature, which is a very important and variable characteristic of the soil, in relation to root system development [9]. Other developments could be imagined, concerning not only the growth response, but also the branching response (via the branching density), to different soil characteristics.

Another step has been achieved through the work of Clausnitzer and Hopmans [7], who simulated with a dynamic model both the effects of several characteristics on root growth (temperature, water potential and soil bulk density) and the modification of soil water potential during root development due to water uptake.

\section{Taking into account an endogenous environment (photo-assimilates)}

One of the major limitations of these modelling approaches is that the development of each root 
within the root system is calculated without taking into account the other roots of the system. Roots are considered as independent from one to another.
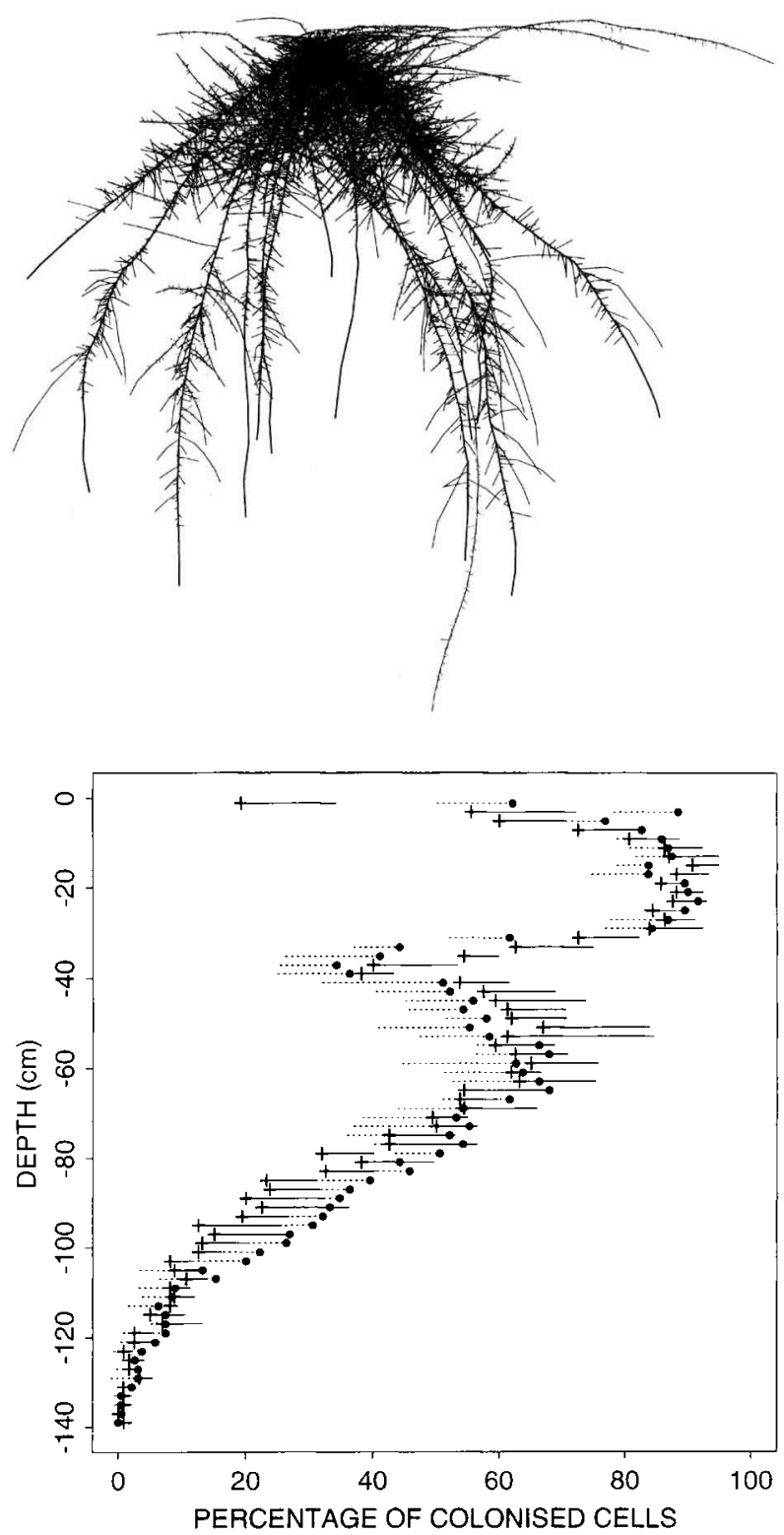

Figure 3. Simulation of the root system architecture in a heterogeneous environment, with a plough pan at a depth of $35 \mathrm{~cm}$ (after Doussan and Pagès, unpublished results). A) General morphology of a simulated maize plant. B) Simulated $(+)$ and observed $(\bullet)$ root profiles, obtained by counting the number of colonised cells $(2 \mathrm{~cm} \times 2 \mathrm{~cm})$ on vertical grids. The horizontal bars represent the standard deviation.
However, many experiments have shown growth correlations within the root system, which can become quantitatively important when the environment is heterogeneous. For example, when a root encounters an obstacle, it generally responds by reducing or stopping its growth [25]. But in such a situation, some of the lateral roots also respond, increasing their growth rate, although their direct exogenous environment has not been changed. The same kind of behaviour can be observed with regards the nutrient heterogeneities. Drew et al. [12] showed that when a root enters a nutrientenriched zone, its lateral roots developed within the zone become more vigorous, whereas the other roots, especially those located at the periphery of the zone, exhibit a decreased growth rate. Here again, these laterals outside the nutrient-enriched zone are responding to an endogenous environment, which has changed, rather than to the exogenous environment. Another example is provided by the multiple synchronisms that exist within the plant, especially between the root and shoot system. Thaler and Pagès [32] showed in rubber tree, a rhythmic habit species, that some roots ceased growing during leaf expansion, and resumed growing during leaf rest.

All of these experiments show that roots are not independent, and that they can be considered to respond to an endogenous context, which can change over time, according to the development stage and stimuli experienced by other organs.

In order to describe these important interactions, it has been suggested to consider the competition for carbohydrates that occurs within the root system [7] or within the whole plant [32]. Competition for carbohydrates has often been considered to be a major determining factor which can explain many phenomena of this sort (see the review of Coutts [8]).

A modelling approach for carbohydrate competition has been attempted through so-called 'source-sink models. In these models, the source organs (the leaves) provide a pool of carbohydrates which is allocated to the different sink organs, either through priority rules, or by equal sharing, in accordance with a demand. In these models, the 
sink strength is a key concept for determining the demand and therefore the actual allocation.

Clausnitzer and Hopmans [7] proposed merging an architectural model (using the previously defined concepts) with a source-sink model, by attributing a potential growth curve to each root type. This curve allowed calculation of a demand at each time step (related to the potential growth rate at that time). The demand was more or less satisfied (as defined by the satisfaction coefficient) depending on the ratio of the total carbohydrate amount to the sum of all individual demands. This approach allows simulation of compensation growth. When the total demand of the root sinks is lowered, for instance because some roots are located in an unfavourable zone where their demand is lowered, other roots can take advantage of the situation, and gain a higher satisfaction coefficient.

Nevertheless, this model requires the definition, a priori, of a fixed potential growth curve for each emerging root. This pre-definition still requires a pre-fixed typology of the roots, and does not allow simulation of the high plasticity of growth patterns that is observed. In particular, each given root type should be given either a determinate or an indeterminate growth pattern, whereas experiments have shown that this growth pattern can be changed when the growth context of a root is changed. For example (see [25]), when a root encounters an obstacle and stops growing, some of its laterals, which would normally show a determinate growth, can acquire an indeterminate growth pattern, as their mother root.

In order to account for these phenomena, Thaler and Pagès [33] suggested consideration of an instantaneous sink strength of the root meristem related to its apical diameter (figure 4). The apical diameter is highly correlated to the cell number in the meristem, and is assumed to define a potential growth rate and hence a carbohydrate demand. Furthermore, in this model, the apical diameter (and so the demand) is not a fixed characteristic. It can decrease when the carbohydrate supply is low (giving a low satisfaction coefficient) and it can increase when the carbohydrate supply is not limiting (high satisfaction coefficient). This modelling

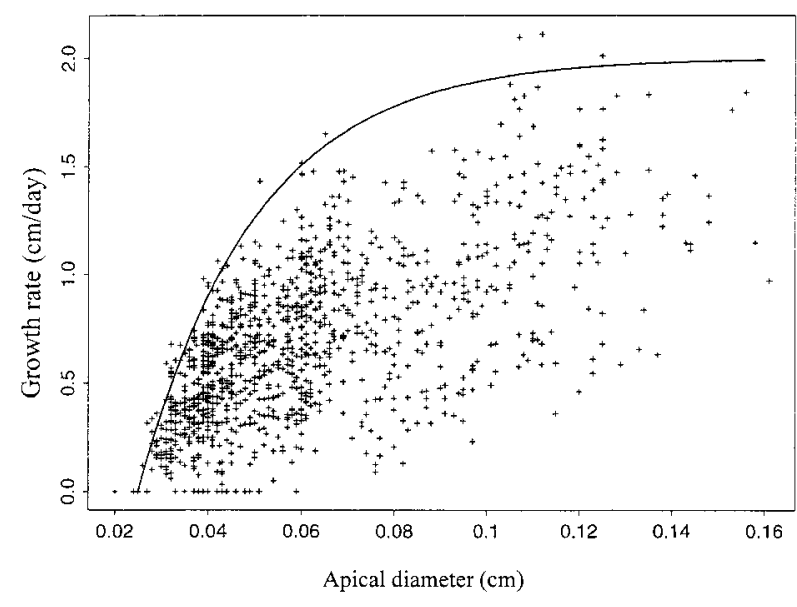

Figure 4. Relationship between root growth rate and apical diameter in rubber tree seedlings (after [33]). The curve represents a potential growth rate.

approach allows the simulation of a larger range of root growth patterns, each specific growth pattern depending first on the initial apical diameter (at the time of emergence), and second on carbohydrate availability during the life course of the root (figure 5). The root is assumed to stop growing when its apical diameter becomes lower than a given threshold.

In both models [7, 33], the endogenous context is represented through the availability of photoassimilates, and is considered globally, at the plant level. This kind of approach could be made more general in the future by considering other substrates or signals contributing to the definition of the endogenous environment (nitrogen availability for example), and also considering heterogeneities of this environment within the architecture, in relation to the resistances to transfer in the roots.

\section{Conclusion}

Modelling root system architecture is a new way to represent the main morphological characteristics of root systems. This modelling approach provides a much more detailed description than the so- 


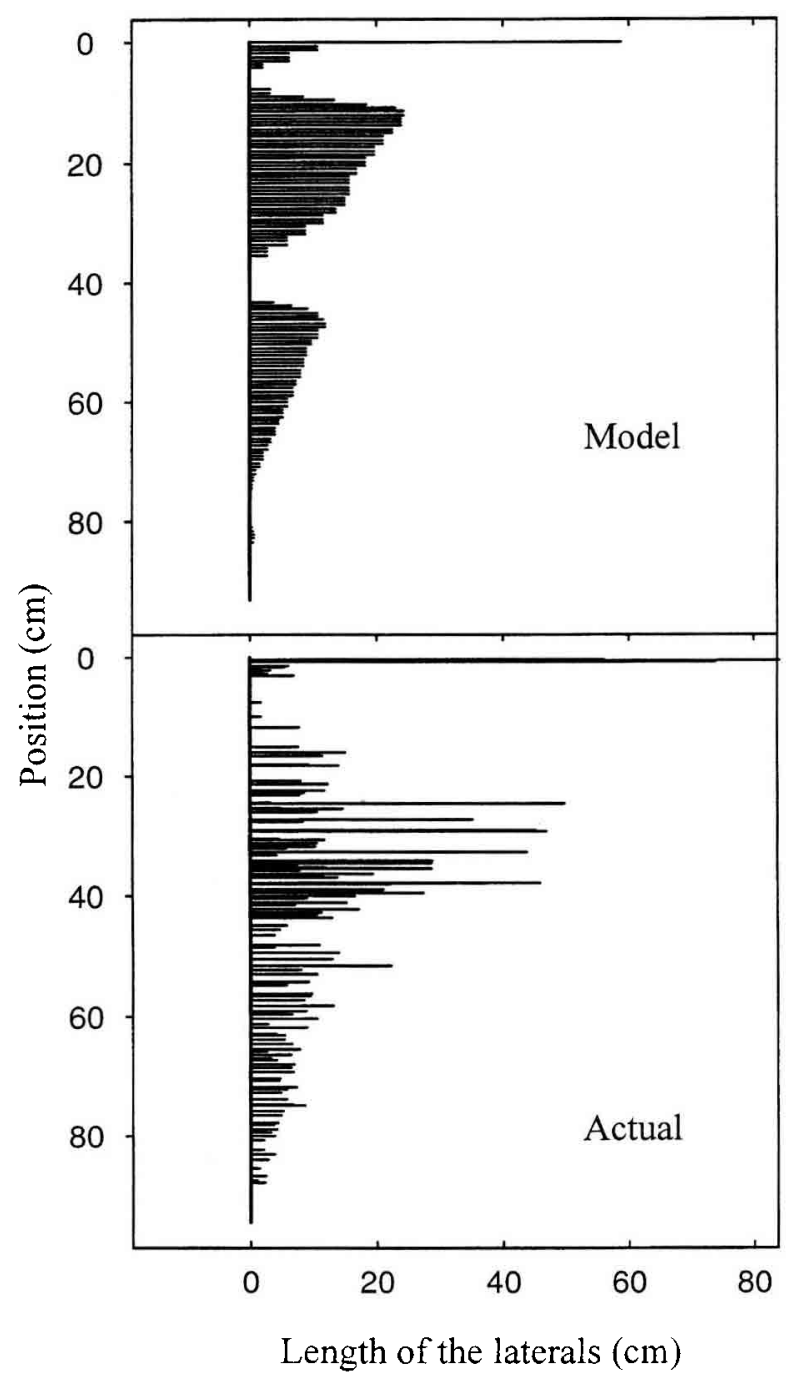

Figure 5. Distribution of lateral root length along the taproot, as observed and simulated on rubber tree seedlings (after [33]). The shortest lateral roots are developed during the period of high leaf growth, and the longest lateral roots are developed during the period of leaf rest.

called root length density models, because it includes both explicit geometrical characteristics (spatial co-ordinates of root segments or root cylinders) and structural characteristics (between segment connections, age, etc.). These detailed and concrete descriptions open new avenues for collaboration with scientists working in other related fields (root morphogenesis, water and nutrient uptake and transport, mycorhizae, biomechanics, etc.). An example of such a collaboration is given by the work of Doussan et al. [10, 11] on water uptake and transport. Water uptake by the root system depends on both its spatial distribution (soil transport) and on its structure, because the radial and axial hydraulic resistances vary among and along the roots, and in relation to their connections. Therefore, it is obviously fruitful to merge the developmental information given by architectural models with the hydraulic characteristics of the roots in order to obtain a dynamic hydraulic architecture.

A problem often expressed concerning these models is that they are complex, with a high number of parameters. We think that the complexity which is emphasised, in comparison to models that simulate root length density, is essentially an apparent one. This appearance relies mainly on the high number of entities (components of the root system) which are handled by the model. The repetition and combination of production rules throughout the root system can generate a very large number of roots, as occurs in real root systems. In contrast, the basic rules are rather simple, and often easy to understand because they rely on concrete objects. Translating some of the concepts from morphogenesis, such as tropisms or branching, is much more straightforward and easy with this modelling approach than through root length density models. It is generally true that architectural models tend to have numerous parameters. Nevertheless, the global number of parameters is obviously not the most relevant criterion for assessing the interest or simplicity of a model. In architectural models, many parameters have a straight biological signification and are independent. This straight signification allows direct estimation by observation or experiment. Their independence guarantees that the estimation error associated with each parameter has no correlative consequences on the others.

The modelling developments that are presented in this paper reflect a gradual change in the goals that have been achieved by these architectural models. 
The first goals were mainly to provide virtual root systems, such as mock-ups, as inputs for other models (uptake models especially). This goal appeared clearly in the works from Lungley [20], Diggle [9] or Pagès and Aries [23]. These dynamic mock-ups also proved to be helpful for investigating methodological problems [5, 29]. Many sampling designs could be tested with these virtual root systems, whose characteristics are completely known, because they were simulated with an explicit model. A model of the experiment, for example a model of minirhizotron observations [29], was applied in addition to the model root systems.

Architectural models also appeared as relevant tools for linking global - at the root system level and local - at the root level - information on root system development and interactions with the soil [7]. These models help to answer the question: Is it possible to model the complicated morphology of root systems through the developmental behaviour of their different parts, which encounter heterogeneous conditions?

In the most recent works [7, 33], a more integrated approach is proposed, in which the components of the root system, which appear according to a morphogenetic programme, interact by contributing and responding to the endogenous context of resource availability.

Acknowledgement: I would like to thank Dr Claude Doussan and an anonymous referee for their comments and corrections on the previous version of the manuscript.

\section{References}

[1] Asseng S., Richter C., Wessolek G., Modelling root growth of wheat as the linkage between crop and soil, Plant Soil 190 (1997) 267-277.

[2] Atger C., Edelin C., Premières données sur l'architecture comparée des systèmes racinaires et caulinaires, Can. J. Bot. 72 (1994) 963-975.

[3] Barber S.A., Soil Nutrient Bioavailability: A Mechanistic Approach, 2nd ed., John Wiley, New York, 1995.
[4] Barthélémy D., Edelin C., Hallé F., Architectural concepts for tropical trees, in: Holm-Nielsen L.B., Nielsen I., Balslei H. (Eds.), Tropical Forests, Botanical Dynamics, Speciation, and Diversity, Academic Press, London, 1989.

[5] Bengough A.G., Mackenzie C.J., Diggle A.J., Relations between root length densities and root intersections with horizontal and vertical planes using root growth modelling in 3 dimensions, Plant Soil 145 (1992) 245-252.

[6] Brown T.N., Kulasiri D., Simulation of Pinus Radiata root system structure for ecosytem management applications, Simulation 62 (1994) 286-294.

[7] Clausnitzer V., Hopmans J.W., Simultaneous modeling of transient three-dimensional root growth and soil water flow, Plant Soil 164 (1994) 299-314.

[8] Coutts M.P., Developmental processes in tree root systems, Can. J. For. Res. 17 (1987) 761-767.

[9] Diggle A.J., ROOTMAP - a model in threedimensional co-ordinates of the growth and structure of fibrous root systems, Plant Soil 105 (1988) 169-178

[10] Doussan C., Pagès L., Vercambre G., Modelling the hydraulic architecture of root systems: An integrated approach of water absorption. I. Model description, Ann. Bot. 81 (1998) 213-223.

[11] Doussan C., Vercambre G., Pagès L., Modelling the hydraulic architecture of root systems: An integrated approach of water absorption. II. Distribution of conductances and consequences, Ann. Bot. 81 (1998) 225-232.

[12] Drew M.C., Saker L.R., Ashley T.W., Nutrient supply and the growth of the seminal root system of barley. I. The effects of nitrate concentration on the growth of axes and laterals, J. Exp. Bot. 24 (1973) 1189-1202.

[13] Feddes R.A., Bresler E., Neuman S.P., Field test of a modified numerical model for water uptake by root systems, Water Resour. Res. 10 (1974) 1199-1206.

[14] Fitter A.H., Stickland T.R, Harvey M.L., Wilson G.W., Architectural analysis of plant root systems. 1. Architectural correlates of exploitation efficiency, New Phytol. 118 (1991) 375-382.

[15] Gerwitz A, Page ER., An empirical mathematical model to describe plant root systems, J. Appl. Ecol. 11 (1974) 773-781.

[16] Huck MG, Hillel D., A model of root growth and water uptake accounting for photosynthesis, respiration, transpiration, and soil hydraulics, Adv. Irrig. 2 (1983) 273-333. 
[17] Jourdan C., Rey H., Guédon Y., Architectural analysis and modelling of the branching process of the young oil-palm root system, Plant Soil 177 (1995) $63-72$.

[18] Lafolie F., Bruckler L., Tardieu F., Modelling root water potential and soil-root water transport: I model presentation, Soil Sci. Soc. Am. J. 55 (1991) 1203-1212.

[19] Le Roux Y., Pagès L., Développement et polymorphisme racinaire chez de jeunes semis d'hévéa (Hevea brasiliensis), Can. J. Bot. 72 (1994) 924-932.

[20] Lungley D.R., The growth of root systems: a numerical computer simulation model, Plant Soil 38 (1973) 145-159.

[21] Lynch J., Root architecture and plant productivity, Plant Physiol. 109 (1995) 7-13.

[22] Nielsen K.L., Lynch J.P., Jablokow A.G., Curtis P.S., Carbon cost of root systems: an architectural approach, Plant Soil 165 (1994) 161-169.

[23] Pagès L., Aries F., SARAH: modèle de simulation de la croissance, du développement, et de l'architecture des systèmes racinaires, Agronomie 8 (1988) 889-896.

[24] Pagès L., Chadoeuf J., Kervella J., Modélisation stochastique de la croissance et du développement du système racinaire de jeunes pêchers. I. Estimation et validation du modèle, Agronomie 12 (1992) 447-458.

[25] Pagès L., Pierre N., Petit P., Growth correlations within the root system of young oak trees, in: Kutschera L., Hübl E., Lichtenegger E., Persson H., Sobotik M. (Eds.), Root Ecology and its Practical Applications, Verein für Wurzelforschung, Klagenfurt, 1992, pp. 505-508.

[26] Pagès L., Jordan M.O., Picard D., A simulation model of the three-dimensional architecture of the maize root system, Plant Soil 119 (1989) 147-154.
[27] Pagès L., Le Roux Y., Thaler P., Modélisation de l'architecture racinaire de l'hévéa, Plantations, Rech. Dév. 2 (1995) 19-34.

[28] Pagès L., Pellerin S., Evaluation of parameters describing the root system architecture of field grown maize plants (Zea mays L.). II. Density, length, and branching of first-order lateral roots, Plant Soil 164 (1994) 169-176.

[29] Pagès L., Bengough A.G., Modelling minirhizotron observations to test experimental procedures, Plant Soil 189 (1997) 81-89.

[30] Pellerin S., Pagès L., Evaluation of parameters describing the root system architecture of field-grown maize plants (Zea mays L.). I. Elongation of seminal and nodal roots and extension of their branched zone, Plant Soil 164 (1994) 155-167.

[31] Prusinkiewicz P., Lindenmayer A., The Algorithmic Beauty of Plants, Springer-Verlag, New York, 1990.

[32] Thaler P., Pagès L., Periodicity in the development of the root system of young rubber trees. Relationship with shoot development, Plant Cell Environ. 19 (1996) 56-64.

[33] Thaler P., Pagès L., Modelling the influence of assimilate availability on root growth and architecture, Plant Soil 201 (1998) 307-320.

[34] Vercambre G., Pagès L., Architecture racinaire du pêcher en conditions de verger. Utilisation d'un modèle pour lier des observations statiques et simuler une dynamique de mise en place, in: Architecture et modélisation en Arboriculture fruitière, $11^{\mathrm{e}}$ Colloque sur les recherches fruitières, Inra-CTIFL, Montpellier, 1998, pp. 286-292.

[35] Waisel Y, Eshel A., Multiform behavior of various constituents of one root system, in: Waisel Y., Eshel A., Kafkafi U. (Eds.), Plant Roots, the Hidden Half, Dekker, New York, 1991, pp. 3-24. 